(highest vs. lowest category $\mathrm{HR}=1.98,95 \% \mathrm{CI}: 0.94-4.16, \mathrm{p}=$ 0.07 , trend $\mathrm{HR}=1.23,95 \% \mathrm{CI}: 0.96-1.57, \mathrm{p}=0.10$ ) and when BMI was included (trend $\mathrm{HR}=1.21,95 \% \mathrm{CI}: 0.94-1.55, \mathrm{p}=$ $0.13)$.

Conclusion The association between PA and cancer risk is dependent on the age at which PA is measured. This possibly reflects occupational activity and differences in general medical health with age or residual confounding. The associations were similar when adjusted for BMI, suggesting an independent mechanism of PA. If the inverse association of increased PA in younger participants is causal, one in six cases of pancreatic cancer might be prevented by encouraging more PA. Aetiological studies should measure PA at different ages when investigating pancreatic cancer. Disclosure of Interest None Declared.

\section{PTH-093 CHROMOGRANIN-A : CAN IT PREDICT RADIOLOGICAL PROGRESSION IN NEUROENDOCRINE TUMOURS?}

${ }^{1,2}$ RE Rossi, ' $\mathrm{J}$ Garcia-Hernandez, ${ }^{3} \mathrm{NG}$ Martin, ${ }^{1} \mathrm{M}$ Mullan, ${ }^{4} \mathrm{~T}$ Meyer, ${ }^{4} \mathrm{C}$ Thirlwell, 5 Watkins, 'ME Caplin, ${ }^{1} \mathrm{C}$ Toumpanakis*. 'Neuroendocrine Tumour Unit, Centre for Gastroenterology, Royal Free Hospital, London, UK; ${ }^{2}$ Postgraduate School of Gastroenterology, Universita'degli Studi Di Milano, Milan, Italy; ${ }^{3}$ Department of Clinical Biochemistry, Royal Free Hospital, London, UK; ${ }^{4}$ Cancer Institute, University College London, Huntley Street, London, UK; ${ }^{5}$ Department of Histopathology, Royal Free Hospital, London, UK

\subsection{6/gutjnl-2014-307263.539}

Introduction Chromogranin $\mathrm{A}(\mathrm{CgA})$ is considered as the best general marker for the diagnosis and follow-up of neuroendocrine tumours (NETs) and is also of prognostic value. In literature, there are no available studies which analysed the role of $\mathrm{CgA}$ as a predictor of radiological disease progression in all NETs. Present study investigates the prognostic value of $\mathrm{CgA}$ as a predictor of radiological disease progression in NET patients. Methods Patients with metastatic NETs and evidence of Radiological Progression (RP) according to RECIST 1.1 were identified from a NET database. Plasma CgA were measured 6 and 12 months before RP and at the event of RP. CgA was measured with the Supra-regional-Assay-Service radioimmunoassay (Hammersmith Hospital), normal value $<60 \mathrm{pmol} / \mathrm{L}$. The tumours were graded according to the 2010 WHO classification, as G1 (Ki67 <2\%), G2 (Ki67: 2-20\%), G3 (Ki67 > 20\%).

Results 152 patients were evaluable including 91 midgut NET and 61 pancreatic NETs (PNETs). Of these, 56 were G1 NETs, 65 G2, 10 G3, 21 of unknown histology. 95.4\% of the patients had liver metastases, whereas bone and lung metastases were present in a smaller proportion of patients (27.6 and 9.9\%, respectively). Median CgA for all NETs 6 months before RP was $213 \mathrm{pmol} / \mathrm{L}$ [Interquartile $1(\mathrm{Q} 1)=67$ and $3(\mathrm{Q} 3)=664.5 \mathrm{pmol} /$ L] compared to $166 \mathrm{pmol} / \mathrm{L}$ (Q1 52, Q3 $535 \mathrm{pmol} / \mathrm{L}$ ) one year before RP, $\mathrm{T}=598.5, \mathrm{p}=0.07$. Significant results were found for PNETs [median CgA 6 months before RP: 100 pmol/L (Q1 53, Q3 $286.25 \mathrm{pmol} / \mathrm{L}$ ) and at 12 months: $52 \mathrm{pmol} / \mathrm{L}$ (Q1 36.25 , Q3 $128 \mathrm{pmol} / \mathrm{L}), \mathrm{T}=52, \mathrm{p}=0.048$ ], but not for midgut NETs [median CgA 6 months before RP: 389.5 pmol/L (Q1 131.5, Q3 $791.5 \mathrm{pmol} / \mathrm{L}$ ) and at 12 months: $319 \mathrm{pmol} / \mathrm{L}$ (Q1 158, Q3 $753 \mathrm{pmol} / \mathrm{L}), \mathrm{T}=191, \mathrm{p}=.39$ ]. Both midgut and PNETs CgA values were significantly higher at RP than 12 months before $[267 \mathrm{pmol} / \mathrm{L}(\mathrm{Q} 1=66, \mathrm{Q} 3=777)$ vs. $166 \mathrm{pmol} / \mathrm{L}$ $(\mathrm{Q} 1=52, \mathrm{Q} 3=535), \mathrm{T}=394.5, \mathrm{p}=0.03]$. Overall, $\mathrm{G} 1$ tumours had median $\mathrm{CgA}$ value at 6 months significantly higher than at 12 months $[181(\mathrm{Q} 1=56.25, \quad \mathrm{Q} 3=624)$ vs. $149.5 \mathrm{pmol} / \mathrm{L}$ $(\mathrm{Q} 1=44, \mathrm{Q} 3=247.25), \mathrm{T}=70, \mathrm{p}=0.048]$.
Conclusion CgA seems to have predictive value 6 months prior to RP for PNETs and G1 tumours, which may be of value to identify specific subgroups of patients who may benefit from a more aggressive follow-up with possible early intervention in case of increased CgA levels. Further prospective studies are needed to enable more definitive conclusions.

\section{REFERENCES}

1 Oberg $\mathrm{K}$ et al. Pancreas 2011

2 Ter-Minassian M et al. Endocr Relat Cancer 2013

3 Welin S et al. Neuroendocrinology 2009

4 Jensen KH et al. Scand J Gastroenterol 2013

Disclosure of Interest None Declared.

\section{PTH-094 BENEFIT OF REAL TIME CYTOLOGICAL EXAMINATION IN EUS GUIDED BIOPSY OF SUSPECTED PANCREATIC MALIGNANCY}

${ }^{1} \mathrm{D}$ Lloyd*, ${ }^{2} \mathrm{~A}$ Al-Badri, ${ }^{1} \mathrm{H}$ Gordon. 'Gastroenterology, Hampshire Hospitals NHS Foundation Trust, Winchester, UK; ${ }^{2}$ Histopathology, Hampshire Hospitals NHS Foundation Trust, Winchester, UK

\subsection{6/gutjnl-2014-307263.540}

Introduction Endoscopic ultrasound (EUS) guided sampling of advanced malignant pancreatic lesions is increasingly being performed in order to confirm malignancy prior to chemotherapy and/or radiotherapy. The Royal Hampshire County Hospital provides EUS services for central and north Hampshire. Prior to mid-2013 there was no facility for examination of cytological specimens during EUS procedures. In line with national commissioning guidelines, a real time pathology service allowing cytological examination during the EUS procedure was instigated from $1^{\text {st }}$ July 2013. The aim of this study was to assess the impact of real time cytological examination on the yield of EUS guided sampling of suspected malignant pancreatic mass lesions. Methods All patients with suspected pancreatic malignancy undergoing EUS guided tissue sampling over a 1 year period from $1^{\text {st }}$ January 2013 to $31^{\text {st }}$ December 2013 were prospectively audited. Note was made of whether real time cytological examination was perfomed by a technician \pm histopathologist. Other data collected included type of needle used, number of passes made with the biopsy needle and total duration of procedure. The diagnostic yield of EUS guided pancreatic sampling was compared with and without real time cytological examination.

Results Twenty-seven procedures were performed over the 12 month period. The majority ( 25 procedures) were performed using Procore ${ }^{\mathrm{TM}}$ fine needle biopsy (FNB) needles. Seventeen procedures were performed without real time cytological examination. Of these, $14(82 \%)$ yielded positive cytology, 1 yielded negative cytology $(6 \%)$ and there was insufficient tissue in 2 $(12 \%)$ cases. Ten procedures were performed with real time cytological examination and of these all yielded positive cytology. Median number of passes made with the biopsy needle was 2 (range 2-3) without real time cytological examination versus 2 (range 1-4) with real time cytological examination. Mean procedure duration was $30( \pm 12)$ min without real time cytological examination versus $36( \pm 15)$ min with real time cytological examination.

Conclusion In our centre, the diagnostic yield of EUS guided sampling of suspected malignant pancreatic mass lesions without real time cytological examination was $82 \%$ which is in line with published data ${ }^{1}$ However, the addition of real time cytological 
examination improved yield to $100 \%$ without significantly lengthening the procedure duration.

\section{REFERENCE}

1 Hewitt MJ et al. EUS-guided FNA for diagnosis of solid pancreatic neoplasms: a meta-analysis. Gastrointest Endosc 2012; 75(2):319-31

Disclosure of Interest None Declared.

\section{PTH-095 PORTAL HYPERTENSION DUE TO SPLANCHNIC VENOUS THROMBOSIS FOLLOWING OPEN OR SKUNK WIRE NECROSECTOMY OF ACUTE SEVERE PANCREATITIS}

${ }^{1}$ EJ Britton*, 'S Mahoney, ${ }^{2} \mathrm{~J}$ Garry, ${ }^{2} \mathrm{C}$ Halloran, ${ }^{1} \mathrm{P}$ Richardson. ${ }^{1}$ Hepatology, Royal Liverpool University Hospital, Liverpool, UK; ${ }^{2}$ Departmant of Pancreatic Surgery, Royal Liverpool University Hospital, Liverpool, UK

\subsection{6/gutjnl-2014-307263.541}

Introduction Isolated splenic vein thrombosis (ISVT) is a well recognised complication of acute pancreatitis with incidences ranging widely but more recently in a large meta analysis reported as approximately $14 \%$ with a reported incidence of varices of $53 \%$ and a GI haemorrhage rate of $12.3 \%$. There is however less available published data on the incidence and natural history of splanchnic vein thrombosis that occurs with severe necrotizing pancreatitis requiring percutaneous or open necrosectomy.

Our aim was to retrospectively review all patients who underwent minimal access retroperitoneal pancreatic necrosectomy (MARPN) at RLUH from 1998 to 2012 to assess the incidence, natural history and complications of splanchnic vein thrombosis. Methods Using a hospital held database we identified all patients who had undergone MARPN or open necrosectomy and had an electronic hospital record. We assessed patient characteristics the incidence of splanchnic vein thrombosis at presentation, at most

\begin{tabular}{lll} 
Abstract PTH-095 Table 1 & & \\
\hline & Number & Percentage \\
\hline Portal venous occlusion at most recent imaghing & 90 & 62.07 \\
3 vessel & 10 & 6.90 \\
2 vessel & 18 & 12.41 \\
1 vessel & 62 & 42.76 \\
Recanalisation & 7 & 4.83 \\
Developed occlusion since admission & 6 & 11.1 \\
Endoscopy in patients with vessel occlusion & 31 & 34.44 \\
Varices & 12 & 38.71 \\
UGIB & 2 & 6.45 \\
\hline
\end{tabular}

recent cross sectional imaging, complications of portal hypertension including incidence of varices and variceal haemorrhage.

Results We identified 191 patients who had undergone necrosectomy. 46 cases were excluded from the final analysis as imaging reports made no comment on the portal venous system. The mean age was 56.1 years with a mean apache score of 9 on admission. Overall 31.7\% $(\mathrm{n}=46)$ underwent open necrosectomy and $68.3 \%$ MARPN necrosectomy. The results are outlined in Table 1.

Conclusion The incidence of splanchnic venous thrombosis in pancreatitis requiring necrosectomy is much higher than previously reported cases series assessing ISVT in patients with acute pancreatitis. The true natural history remains splanchnic venous thrombosis related to pancreatitis remains unknown, however in our case series the recanalisation rate was low. However in severe necrotizing pancreatitis portal venous complications should be actively investigated and UGI endoscopy to examine for varices should be carried out such that prophylaxis against variceal haemorrhage can be used where appropriate.

Disclosure of Interest None Declared.

\section{PTH-096 THE SENSITIVITY OF EUS FNA OF SOLID PANCREATIC LESIONS, WORKING FROM A REGIONAL MDT AND WITHIN A REGIONAL NETWORK}

${ }^{1} \mathrm{H}$ Gordon ${ }^{*},{ }^{1} \mathrm{D}$ Lloyd, ${ }^{2} \mathrm{~A}$ Higginson, ${ }^{3} \mathrm{R}$ McCrudden, ${ }^{4} \mathrm{C}$ Bent, ${ }^{5} \mathrm{~F}$ Shek, ${ }^{2} \mathrm{R}$ Beable, ${ }^{6} \mathrm{~A}$ AlBadri, ${ }^{7} \mathrm{~B}$ Green, ${ }^{7} \mathrm{E}$ Jaynes, ${ }^{8} \mathrm{D}$ Collins, ${ }^{2} \mathrm{D}$ Poller, ${ }^{5} \mathrm{~B}$ Stacey. ${ }^{1}$ Gastroenterology, Hampshire Hospitals Foundation Trust, Winchester, UK; ${ }^{2}$ Radiology, Queen Alexandra Hospital, Portsmouth, UK; ${ }^{3}$ Gastroenterology, Royal Bournemouth County Hospital, Bournemouth, UK; ${ }^{4}$ Radiology, Royal Bournemouth County Hospital, Bournemouth, UK; ${ }^{5}$ Gastroenterology, University Hospital Southampton, Southampton, UK; ${ }^{6}$ Histopathology, Hampshire Hospitals Foundation Trust, Winchester, UK; ${ }^{7}$ Histopathology, University Hospital Southampton, Southampton, UK: ${ }^{8}$ Histopathology, Royal Bournemouth County Hospital, Bournemouth, UK

\subsection{6/gutjpl-2014-307263.542}

Introduction Endoscopic ultrasound (EUS) guided sampling of advanced malignant pancreatic lesions is increasingly being performed in order to confirm malignancy prior to chemotherapy and or treatment. Meta-analysis of 33 studies examining solid lesion EUS FNA tissue acquisition in 4984 patients showed a pooled sensitivity of $85 \%$, increasing to $91 \%$ if suspicious atypia was included ${ }^{1}$. Higher sensitivities have been demonstrated in large volume single operator centres where sensitivities of 92$97 \%{ }^{2,3}$ have been reported.

The four Wessex EUS centres all work from a regional HPB MDT, where pancreatic cases are discussed and EUS procedures requested. Each centre has two EUS operators, performing between 148 and 214 cases per annum. Additionally the regional EUS endoscopists, pathologists and biomedical technicians meet

\begin{tabular}{|c|c|c|c|c|c|c|}
\hline & $\begin{array}{l}\text { Number solid pancreatic } \\
\text { masses sampled }\end{array}$ & $\begin{array}{l}\text { Number malignancy } \\
\text { confirmed }\end{array}$ & $\begin{array}{l}\text { False negative } \\
\text { for malignancy on } \\
\text { clinical /radiological findings }\end{array}$ & $\begin{array}{l}\text { Insufficient } \\
\text { sample }\end{array}$ & $\begin{array}{l}\text { True negative } \\
\text { for malignancy, on clinical } \\
\text { /radiological findings }\end{array}$ & Sensitivity \\
\hline Centre 1 & 28 & 24 & 0 & 0 & 4 & $100 \%$ \\
\hline Centre 2 & 14 & 14 & 0 & 0 & 0 & $100 \%$ \\
\hline Centre 3 & 17 & 11 & 0 & 1 & 5 & $92 \%$ \\
\hline Centre 4 & 18 & 15 & 2 & 0 & 1 & $88 \%$ \\
\hline Total & 77 & 64 & 2 & 1 & 10 & $96 \%$ \\
\hline
\end{tabular}

